\title{
Heritability of Serum Iron, Ferritin and Transferrin Saturation in a Genetically Isolated Population, the Erasmus Rucphen Family (ERF) Study
}

\author{
O.T. Njajou ${ }^{a} \quad$ B.Z. Alizadeh ${ }^{a} \quad$ Y. Aulchenko ${ }^{a} \quad$ M.C. Zillikens ${ }^{a} \quad$ H.A.P. Pols ${ }^{a}$ \\ B.A. Oostra ${ }^{a}$ D.W. Swinkels ${ }^{b}$ C.M. van Duijn ${ }^{a}$ \\ ${ }^{a}$ Genetic Epidemiology Unit, Departments of Epidemiology \& Biostatistics and Clinical Genetics, \\ Erasmus University Medical Centre, Rotterdam, ${ }^{b}$ Department of Clinical Chemistry, Radboud University \\ Medical Centre Nijmegen, Nijmegen, The Netherlands
}

\section{Key Words}

Heritability $\cdot$ HFE $\cdot$ Iron $\cdot$ Ferritin $\cdot$ Transferrin saturation •

Genetic isolate

\begin{abstract}
Background: Iron has been implicated in the pathogenesis of various disorders. Mutations in the HFE gene are associated with an increase in serum iron parameters. The aim of this study was to estimate the heritability in serum iron parameters explained by HFE. Methods: Ninety families (980 subjects) were included in the present analysis. Heritability estimation was conducted using the variance component method. The likelihood ratio test was used to compare models. Phenotypic and genetic correlations between serum iron parameters were calculated. Results: The heritability $\left(\mathrm{h}^{2}\right.$ $\pm \mathrm{SE})$ estimates were $0.23 \pm 0.07(p<0.0001)$ for iron, 0.29 $\pm 0.09(p<0.0001)$ for ferritin and $0.28 \pm 0.07(p<0.0001)$ for transferrin saturation while adjusting for age, age $\mathrm{e}^{2}$ and sex. The HFE genotypes explained between 2 to $6 \%$ of the sex and age-adjusted variance in serum iron, ferritin and transferrin saturation. There was a high genetic correlation between serum iron parameters, suggesting pleiotropy between these traits. Conclusion: A substantial proportion of the variance of iron, ferritin and transferrin saturation can be
\end{abstract}

O.T.N. and B.Z.A. contributed equally to this work.

\section{KARGER}

Fax +4161306 1234 E-Mail karger@karger.ch www.karger.com (c) 2006 S. Karger AG, Basel

0001-5652/06/0614-0222\$23.50/0

Accessible online at:

www.karger.com/hhe explained by additive genetic effects, independent of sex and age. The HFE genotypes explained a considerable proportion of serum iron parameters and may be an important factor in the complex iron network.

Copyright $\odot 2006$ S. Karger AG, Basel

\section{Introduction}

Iron plays an important role in biochemical reactions $[1,2]$. Low iron levels are associated with iron deficiency anaemia [2]. Increased iron stores in the body have been linked to several diseases including vascular disease(s) [3, 4], Parkinson's disease [5], diabetes mellitus [6], arthritis [7] and liver diseases [8].

Body iron status is not only influenced by genes but also by environmental factors like diet, iron intake, blood loss, pregnancy, alcohol intake and infections $[9,10]$. In order to maintain iron levels within normal ranges and thus prevent the pathologic consequences of iron excess or iron deficiency, iron homeostasis has evolved as a complex trait and a tightly coordinated process of interplay between genes and environmental factors in order to maintain iron levels within the normal range. Several genes are known that are involved in iron regulation in humans including the hereditary hemochromatosis gene (HFE), the ferroportin1 gene (FPN1), the divalent metal transporter gene (DMT1), the hepcidin antimicrobial

Dr. Omer T. Njajou

Department of Epidemiology \& Biostatistics

Erasmus University Medical Center Rotterdam, P.O. Box 1738

NL-3000 DR Rotterdam (The Netherlands)

Tel. +31 10408 7391, Fax +31 10408 9382, E-Mail o.njajou@erasmusmc.nl 
peptide (HAMP), the hemochromatosis type 2 gene (HFE2), and the transferin receptors gene (TFR) [11-16]. Mutations in these genes have been implicated in hereditary hemochromatosis, a disorder of iron metabolism, in which there is increased absorption and storage of iron in body tissues. The common and most important gene is HFE. The HFE gene has two main mutations, the C282Y and the H63D mutations. These two mutations are found in $85 \%$ of patients with hemochromatosis and are also associated with increased body iron concentrations in the general population [13]. HFE mutations are not fully penetrant and their contribution to the overall genetically determined variation in iron pool has not been clearly established.

Crawford et al. [17] studied the concordance of iron storage in siblings with genetic hemochromatosis. They found that siblings of similar sex accumulate similar amounts of liver iron. Their study demonstrated that iron storage in hemochromatosis is predominantly under genetic control. In a similar study, Whiting et al. [18] reported a concordance of iron indices in C282Y homozygote(s) and heterozygote(s) sibling pairs. There is only one twin study known on the heritability of iron parameters. Whitfield et al. [19] reported that 23 and $31 \%$ of the variance in iron, 66 and $49 \%$ of the variance in transferrin, 33 and $47 \%$ of the variance in transferrin saturation and 47 and $47 \%$ of the variance in ferritin, in men and women respectively, could be explained by additive genetic factors. However, this study did not address the question to what extend serum iron parameters are explained by known genes such as HFE. Lazarescu et al. [20] reported a residual heritability of $35 \%$ for serum ferritin in subjects with the $\mathrm{C} 282 \mathrm{Y}$ genotype. Their study did not address other valuable iron parameters like serum iron and serum transferrin saturation, which are important for clinical diagnosis.

We estimated the proportion of serum iron, ferritin and transferrin saturation due to genetic factors and the proportion that could be explained by the HFE gene using a large family-based sample from a genetically isolated population in the Netherlands. Further, we estimated the genetic and phenotypic correlations between these traits.

\section{Material and Methods}

\section{Study Population}

This study was carried out within a family-based study of 3,000 inhabitants of a genetically isolated community in the Southwest of the Netherlands, the Erasmus Rucphen Family
(ERF) study. The ERF study has been described in detail elsewhere [21]. Briefly, about 150 people who migrated to the area in the middle of the 18th century founded the study population. Since then there has been little emigration and immigration in the area and considerable population expansion. At present, there are about 20,000 inhabitants all living in 8 adjacent villages. The aim of the ERF study is to unravel the genetic determinants of complex diseases and the medical ethics committee of the Erasmus Medical Centre Rotterdam has approved this study. Informed consent and authorization to inspect and use medical records were obtained from all participants.

\section{Family Structure}

The (first) 980 participants considered in the present study came from 90 families and included 369 parent-offspring pairs, 561 sibling pairs, 41 half-sibling pairs, 872 avuncular pairs, 32 grandparent-grandchild pairs, 52 half avuncular pairs, 2, 258 first cousins pairs, 50 half first cousin pairs.

\section{Phenotypic Measurements}

Participants were invited for a battery of clinical examinations at the research centre. Each participant provided blood samples and further information was obtained during an interview at the research centre and after participants returned a take-home questionnaire. Fasting blood samples were drawn by venepuncture between 7:00 and 10:00 a.m. Serum samples were obtained from whole blood and plasma samples were obtained from blood collected in EDTA.

The serum ferritin was measured by a solid-phase, two-site chemiluminescent immunometric assay (Immulite 2000, Diagnostic Products Corporation, Cirrus). Total serum iron was measured by colorimetric assay with the use of ascorbate/FerroZine reagents from Roche on an Aeroset from Abbott. The unsaturated iron binding capacity (UIBC) was measured by adding a known quantity of Fe(III) to the serum sample, reducing it with ascorbate to $\mathrm{Fe}(\mathrm{II})$ and measuring it with FerroZine as described above (Roche reagents on an Aeroset). The total iron binding capacity (TIBC) was calculated as: $\mathrm{Fe}+\mathrm{UIBC}=\mathrm{TIBC}$. Serum transferrin saturation (\%) was calculated as follows: (serum iron/TIBC) $\times$ $100 \%$. Genotyping of the HFE C282Y and H63D variants were done as described elsewhere [22].

\section{Statistical Analyses}

The heritability of serum iron parameters was estimated using the variance component method as implemented in the program SOLAR [23]. The heritability is calculated by partitioning the phenotypic variance $(\mathrm{Vp})$ of the serum iron parameter into components that include the additive effect of genes or polygenic variance $(\mathrm{Vg})$, the variance due to measured environmental risk factors (Ve) such as age, sex and other covariates, and the residual or non-shared environmental variance $(\mathrm{Vr})$. The heritability is defined as $h^{2}=V g /(V p-V r)$. We accounted for the pedigree structure by using the kinship matrix as a covariate. The kinship matrix captures the proportion of genes shared in common between all pairs of individuals in the family, based on their relationship (sibling(s) pairs share $50 \%$ of their genes in common, grandparent-grandchild pairs share $25 \%$ of their genes in common, unrelated spouses share no gene in common). The likelihood ratio test was used to test for significance. Two times the difference between the log-likelihoods of the two models has a chi-square dis- 
tribution with degree of freedoms equal to the difference in the number of covariates in the models that are being compared.

The association between the traits and HFE polymorphisms was tested by including the genotypes as covariates; the genotypes were coded as number of 'Y' (C282Y) and 'D' alleles (H63D). The proportion of variance explained by inclusion of the genotypes was estimated as $\left(\mathrm{Ve}^{\prime}-\mathrm{Ve}\right) /(\mathrm{Vp}-\mathrm{Ve})$, where Ve is variance explained by sex, age and age ${ }^{2}$ and $\mathrm{Ve}^{\prime}$ is the variance explained by including the above covariates and the genotype. The total significance of the inclusion of HFE genotypes was tested using Likelihood Ratio Test on 2 degrees of freedom.

We further investigated whether significant associations between serum iron parameters could be explained by common genetic influences, shared environmental factors or unmeasured non-genetic factors using bivariate analysis. We partitioned the phenotypic correlation between a pair of quantitative traits into their additive genetic effect and random environmental effect taking into account the kinship correlation.

The significance of the phenotypic, genetic and environmental correlations were evaluated using the likelihood ratio test by comparing the model in which the parameter is set to zero to the model in which the parameter is estimated. The inbreeding coefficient was estimated using the PEDIG package [24]. In all analyses age, age ${ }^{2}$, sex and inbreeding coefficient were included as covariates in the model. Serum iron parameters exhibiting a skewed distribution were normalized prior to data analysis.

\section{Results}

The characteristics of the study population are shown in table 1. In total of 980 subjects were included in the analysis and consisted of a large number of relative pairs, including 894 first-degree relative pairs, 652 second-degree relative pairs and 2,360 third degree relative pairs. The mean serum iron, ferritin and transferrin saturation for men and women are presented in table 1. Our reference range for iron was $10-25 \mu \mathrm{mol} / \mathrm{l}$ and $15-50 \%$ for transferrin saturation. The reference ranges for ferritin are not uniform, due to less optimal standardization. Therefore reported ferritin values vary greatly between laboratories. Our reference values for ferritin were 15$280 \mu \mathrm{g} / \mathrm{l}$ for men, $6-80 \mu \mathrm{g} / \mathrm{l}$ for premenopausal women and $15-190 \mu \mathrm{g} / \mathrm{l}$ for postmenopausal women.

Figure 1 shows the mean serum iron, ferritin and transferrin saturation by HFE C282Y genotype. Serum iron, ferritin and transferrin saturation were significantly higher $(\mathrm{p}<0.001)$ in women homozygous for the $\mathrm{C} 282 \mathrm{Y}$ mutation compared to wild type homozygotes. Although subjects heterozygous for the C282Y mutation had higher serum iron indices compared to wild type homozygotes, this did not reach statistical significance.

Table 2 shows the heritability estimates $\left(\mathrm{h}^{2} \pm\right.$ standard error) for serum iron, serum ferritin and transferrin
Table 1. Characteristics of the study population

$\begin{array}{lc}\text { Men, } \% & 40 \\ \text { Age, years } & 53.52 \pm 0.47 \\ \text { Serum iron, } \mu \mathrm{mol} / \mathrm{l} & 20.96 \pm 0.33 \\ \quad \text { Men } & 18.82 \pm 0.26 \\ \quad \text { Women } & \\ \text { Serum ferritin, ng/ml } & 223.71 \pm 8.84 \\ \quad \text { Men } & 99.34 \pm 4.28 \\ \quad \text { Women } & \\ \text { Serum transferrin saturation, \% } & 35.30 \pm 0.59 \\ \quad \text { Men } & 30.78 \pm 0.45 \\ \quad \text { Women } & 0.006 \pm 0.00004 \\ \text { Inbreeding coefficient } & \end{array}$

Figures are mean \pm standard error or percentage.

saturation. When HFE C282Y and H63D genotypes were considered in the model, the heritability estimates were $0.20 \pm 0.07(\mathrm{p}<0.0001)$ for iron, $0.22 \pm 0.07(\mathrm{p}<0.0001)$ for ferritin and $0.23 \pm 0.07(\mathrm{p}<0.0001)$ for transferrin saturation. The effects of HFE C282Y and H63D genotypes was highly significant ( $\mathrm{p}<0.001$ for all three traits). The effect of the $282 \mathrm{Y}$ allele was $1.49+0.54$ on serum iron level, $80.29+11.23$ on ferritin and $4.34+0.98$ on transferrin saturation. The effect of the $63 \mathrm{D}$ allele was somewhat lower: $1.49+0.44,16.22+9.11$ and $2.81+0.77$ for iron, ferritin and transferrin saturation, respectively. The proportion of variance explained by HFE gene mutations was $2.1 \%$ for serum iron level, $5.6 \%$ for ferritin and $3.5 \%$ for transferrin saturation.

Table 3 shows the phenotypic $(P)$ and genetic $(\mathrm{G})$ correlations between serum iron, serum ferritin and transferrin saturation. As expected, there was a high and significant phenotypic and genotypic correlation between serum iron and serum ferritin.

The genetic correlation estimates vary little between models with and without the HFE genotypes included (data not shown). This suggests that HFE mutations equally affect serum iron, ferritin and transferrin saturation levels or that there are other, even more important pleiotropic genes.

To test the effect of inbreeding on the results presented here, we computed the mean of serum iron parameters by level of inbreeding. We categorised subjects into three categories; no inbreeding (0) for subjects with no inbreeding or inbreeding coefficient $=0$, low inbreeding (1) for subjects with inbreeding coefficient $\leq$ to the mean inbreeding coefficient and high inbreeding coefficient (2) for subjects with inbreeding coefficient $>$ mean inbreed- 


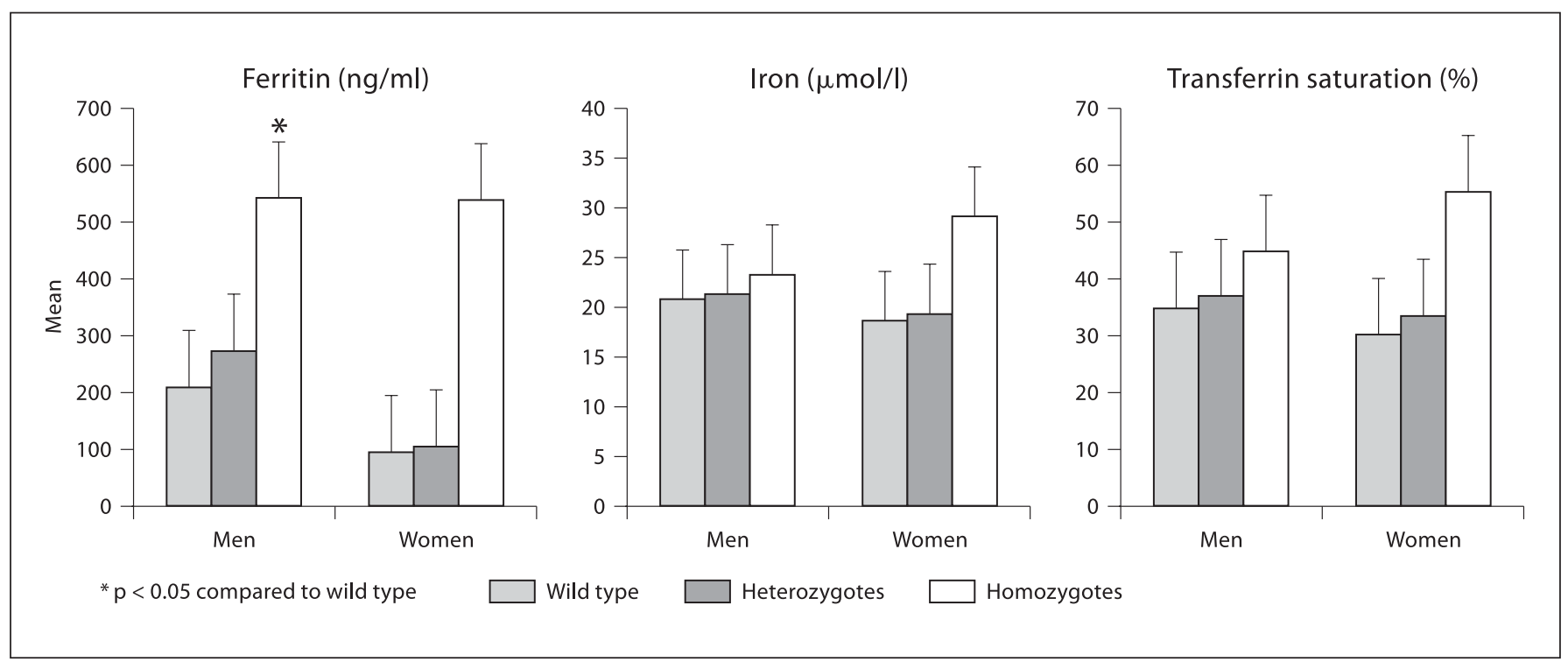

Fig. 1. Mean (SE) level of serum iron indices by C282Y genotype.

Table 2. Heritability $\left(\mathrm{h}^{2}\right)$ estimates of serum iron, ferritin and transferrin saturation

\begin{tabular}{clll}
\hline & Serum iron & Serum ferritin & $\begin{array}{l}\text { Serum transferrin } \\
\text { saturation }\end{array}$ \\
\hline $\begin{array}{l}\text { Covariates } \\
\text { Age }+ \text { sex }+ \text { age }^{2}\end{array}$ & $\begin{array}{l}0.23 \pm 0.07 \\
(\mathrm{p}<0.0001)\end{array}$ & $\begin{array}{l}0.29 \pm 0.09 \\
(\mathrm{p}<0.0001)\end{array}$ & $\begin{array}{l}0.28 \pm 0.07 \\
(\mathrm{p}<0.0001)\end{array}$ \\
$\begin{array}{l}\text { Age }+ \text { sex }+ \text { age }^{2}+\text { HFE } \\
\text { genotypes }\end{array}$ & $\begin{array}{l}0.20 \pm 0.07 \\
(\mathrm{p}<0.0001)\end{array}$ & $\begin{array}{l}0.22 \pm 0.07 \\
(\mathrm{p}<0.0001)\end{array}$ & $\begin{array}{l}0.23 \pm 0.07 \\
(\mathrm{p}<0.0001)\end{array}$
\end{tabular}

Figures are proportion of variance \pm standard error.
Table 3. Phenotypic and genetic correlations between serum iron, ferritin and transferrin saturation
Serum iron and serum ferritin $\quad P=0.25, p<0.001 \quad G=0.40, p<0.001$ Serum ferritin and serum transferrin saturation $P=0.40, p<0.001 \quad G=0.73, p<0.001$

$\mathrm{P}=$ Phenotypic correlation; $\mathrm{G}=$ genetic correlation . ing coefficient. Figure 2 shows the mean iron indices by level of inbreeding. There was a significant difference in mean serum ferritin by level of inbreeding, predicting a recessive model. We observed no significant difference in the mean of serum iron and serum transferrin saturation by level of inbreeding.

Heritability of Serum Iron Parameters

\section{Discussion}

We have studied the contribution of genetic and environmental factors on serum iron indices. We found that a significant proportion of serum iron $(23 \%)$, serum ferritin $(29 \%)$ and transferrin saturation $(28 \%)$ could be attributed to genetic factors. A large proportion of serum iron parameters is determined by environmental factors. We also found that serum iron indices are significantly 
correlated, indicating that they share common genetic and environmental factors.

Compared to the twin study of Whitfield et al. [19], our heritability estimates are somewhat lower. This can be explained by the differences in study populations. We have studied large families from a genetic isolate and we have conditioned on the pedigree structure and accounted for relationship between individuals in our analysis. Heritability estimates from twin studies are based on differences in trait correlations between monozygotic and dizygotic twin pairs and are based on the assumption that environmental influences are the same for both twin pairs whereas differences between dizygotic twin pairs may be attributable to both genetic and environmental factors. Another explanation for the small differences in heritability estimates between these two studies can be the difference in the population's genetic make up as they studied an Australian population comprising subjects of Celtic origin. Celts are known to have a higher frequency of the HFE C282Y mutation and therefore increased iron stores. It is also possible that different methods of measurements of serum iron indices can lead to subtle differences in heritability estimates. We have calculated serum transferrin saturation using TIBC, whereas Whitfield et al. [19] used transferrin. Although some articles suggest that the relation between transferrin and TIBC is not fixed, others found that when each test is measured precisely and without bias, the ratio of TIBC (in $\mu \mathrm{mol} / \mathrm{l}$ ) to transferrin (in $\mathrm{g} / \mathrm{l}$ ) is indeed close to the expected value of $25.0[25,26]$. Also, recent studies found high significant correlations between the TIBC and the serum transferrin values, even without this proposed calibration [27].

Our results in this genetic isolate are comparable to our previous report in another Dutch population [22] where we found that the HFE genotypes explained less than $5 \%$ of the variability in serum ferritin and about $6 \%$ variability in serum transferrin saturation.

The major strength of our study is its population structure. We did not only use related individuals but also included spouses and relatives not living in the same household. This has the advantage of reducing confounding by shared environment leading to more accurate estimates of the genetic effect.

We found that about 20 to $30 \%$ of serum iron indices can be attributed to genetic factors. We also observed a high genetic correlation between serum iron, ferritin and transferrin saturation suggesting that these traits are likely regulated by the same genes. It has been reported that iron regulates ferritin production [28].

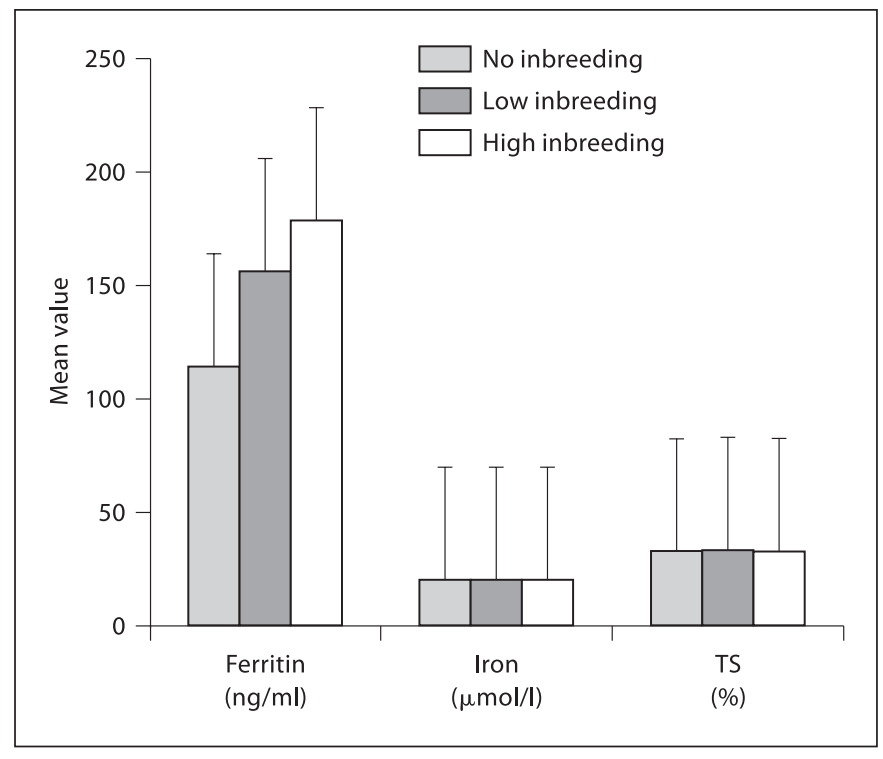

Fig. 2. Mean (SE) iron parameters by degree of inbreeding.

The HFE C282Y and H63D genotypes could explain 2 to $6 \%$ of the sex and age-adjusted variation in iron indices. This is in agreement with the study of Crawford et al. [14] who found a heritability of 3.5\% for serum ferritin in sibs with hemochromatosis. The proportions themselves (2 to $6 \%$ ) may seem small at the first glance. However, for the iron levels and transferrin saturation these effects are comparable to those exhibited by such important factor as sex (2.6\% for iron and $3.7 \%$ for transferrin saturation). Moreover, in the context of genetics of complex traits, an effect size in the magnitude of $5 \%$ is high. For example, a gene that is consistently implicated in human complex genetics is the APOE gene. The e2/e3/e4 polymorphism of this gene explains about 3 to $5 \%$ of the variation of total cholesterol level [29].

The observation of a 2 to $6 \%$ influence of the HFE on a complex trait such as iron points to a significant role of HFE in the complex iron network. This network according to the current knowledge involves numerous other proteins connecting several pathways [30-32]. Also the effect estimate for the C282Y and H63D mutations is in agreement with the observation that heterozygosity for the C282Y mutation in the HFE gene shows increased iron parameters compared to wild type and this mutation is associated with significantly higher iron loading compared to the H63D [22].

Without being the devil's advocate, these results bring back HFE to the central role it had been given just after 
its discovery in 1996 but that appears to have faded away since (i) the clinical penetrance of homozygosity for the C282Y mutation was shown to be low in 2001 [33], and (ii) other proteins of significant importance in iron metabolism were identified the last few years.

The control of iron homeostasis involves numerous genetic and environmental factors that are part of a wide network of metabolic pathways. This regulation appears to take place at both the systemic and cellular level with the intestine, bone marrow, macrophages and hepatocytes as the main regulatory sites and cell types [31]. In recent years, identification and characterization of new transporters, scavengers and regulatory proteins have considerably increased our understanding of iron homeostasis and its link with other pathways, such as innate immunity and signal transduction that have roles in a myriad of biological activities [31, 32]. The newly identified key players of iron metabolism among others include HFE, transferrin receptor 2 (TfR2), ferroportin and hemojuvelin, as well as the iron regulatory protein hepcidin [30]. The latter protein is a small peptide synthesized in the liver in response to the total burden of iron, but also to non-iron stimuli such as inflammation and oxidative stress.

Although the exact role of HFE is not known yet, the available data do suggest that HFE/TfR1 in parallel to
TfR2 is implicated in the iron sensing pathway of hepatocytes that controls hepcidin synthesis (reviewed in [34]). But also HFE in macrophages might influence hepatic hepcidin expression [35].

Altogether, these proteins, signals and regulatory mechanism orchestrate expression of iron genes that involve both genetic and environmental modulation of transcription, translation and post-translational modifications. Thus it is likely that there is a multifactorial influence on serum iron parameters including a multigenetic rather than an oligogenetic effect.

The effect of inbreeding in our study population was significant for serum ferritin only, predicting a recessive mode of inheritance.

Future studies aiming at identifying genes influencing serum iron and ferritin levels in this population are necessary and can be done using a quantitative trait loci (QTL) method.

\section{Acknowledgements}

We thank Mr. Siem Klaver for measurements of serum iron parameters and Mrs. Luba Pardo Cortes for statistical assistance. This study was supported by an Erasmus University Rotterdam Fellowship to Dr. Njajou T. Omer.

\section{References}

1 Sullivan JL: Iron and the genetics of cardiovascular disease. Circulation 1999;100: 1260-1263.

2 Emerit J, Beaumont C, Trivin F: Iron metabolism, free radicals and oxidative injury. Biomed Pharmacother 2001;55:333-339.

- 3 van der A DL, Grobbee DE, Roest M, Marx JJ, Voorbij HA, van der Schouw YT: Serum ferritin is a risk factor for stroke in postmenopausal women. Stroke 2005;36:16371641.

4 de Valk B, Marx JJ: Iron, atherosclerosis, and ischemic heart disease. Arch Intern Med 1999;159:1542-1548.

-5 Sofic E, Riederer P, Heinsen H, Beckmann H, Reynolds GP, Hebenstreit G, Youdim MB: Increased iron (III) and total iron content in post mortem substantia nigra of parkinsonian brain. J Neural Transm 1988;74:199205.

6 Jiang R, Manson JE, Meigs JB, Ma J, Rifai N, Hu FB: Body iron stores in relation to risk of type 2 diabetes in apparently healthy women. JAMA 2004;291:711-717.
7 Li J, Zhu Y, Singal DP: HFE gene mutations in patients with rheumatoid arthritis. J Rheumatol 2000;27:2074-2077.

-8 Fargion S, Mattioli M, Fracanzani AL, Sampietro M, Tavazzi D, Fociani P, Taioli E, Valenti L, Fiorelli G: Hyperferritinemia, iron overload, and multiple metabolic alterations identify patients at risk for nonalcoholic steatohepatitis. Am J Gastroenterol 2001;96: 2448-2455.

9 Andrews NC: Iron homeostasis: insights from genetics and animal models. Nature Rev Genet 2000;1:208-217.

10 Whitfield JB, Zhu G, Heath AC, Powell LW, Martin NG: Effects of alcohol consumption on indices of iron stores and of iron stores on alcohol intake markers. Alcohol Clin Exp Res 2001;25:1037-1045.

11 Papanikolaou G, Samuels ME, Ludwig EH MacDonald ML, Franchini PL, Dube MP, Andres L, MacFarlane J, Sakellaropoulos N, Politou M, Nemeth E, Thompson J, Risler JK, Zaborowska C, Babakaiff R, Radomski CC, Pape TD, Davidas O, Christakis J, Brissot P, Lockitch G, Ganz T, Hayden MR, Goldberg YP: Mutations in HFE2 cause iron overload in chromosome 1q-linked juvenile hemochromatosis. Nature Genet 2004;36:77-82.
12 Montosi G, Donovan A, Totaro A: Autosomal dominant hemochromatosis is associated with a mutation in the ferroportin (SLC11A3) gene. J Clin Invest 2001;108:619623.

13 Feder JN, Gnirke A, Thomas W, Tsuchihashi Z, Ruddy DA, Basava A, et al: A novel MHC class I-like gene is mutated in patients with hereditary hemochromatosis. Nature Genet 1996;13:399-408.

14 Camaschella C, Roetto A, Cali A, De Gobbi M, Garozzo G, Carella M, Majorano N, Totaro A, Gasparini P: The gene TFR2 is mutated in a new type of haemochromatosis mapping to $7 q 22$. Nature Genet 2000;25:1415.

15 Roetto A, Totaro A, Cazzola M, Cicilano M, Bosio S, D'Ascola G, Carella M, Zelante L, Kelly AL, Cox TM, Gasparini P, Camaschella C: Juvenile hemochromatosis locus maps to chromosome 1q. Am J Hum Genet 1999; 64:1388-1393. 
16 Njajou OT, Vaessen N, Joosse M, Berghuis B, van Dongen JWF, Breuning $\mathrm{MH}$, Snijders PJL, Rutten WPF, Sandkuijl LA, Oostra BA, van Duijn CM, Heutink P: A mutation in SLC11A3 is associated with autosomal dominant hemochromatosis. Nature Genet 2001; 28:214-215.

-17 Crawford DH, Halliday JW, Summers KM, Bourke MJ, Powell LW: Concordance of iron storage in siblings with genetic hemochromatosis: Evidence for a predominantly genetic effect on iron storage. Hepatology 1993; 17:833-837.

18 Whiting PW, Fletcher LM, Dixon JK, Gochee P, Powell LW, Crawford DH: Concordance of iron indices in homozygote and heterozygote sibling pairs in hemochromatosis families: implications for family screening. J Hepatol 2002;37:309-314.

19 Whitfield JB, Cullen LM, Jazwinska EC, Powell LW, Heath AC, G, Zhu, Duffy DL, Martin NG: Effect of HFE C282Y and H63D polymorphisms and polygenic background on iron stores in a large community sample of twin. Am J Hum Genet 2000;66:12461259.

20 Lazarescu A, Snively BM, Adams PC: Phenotype variation in $\mathrm{C} 282 \mathrm{Y}$ homozygotes for the hemochromatosis gene. Clin Gastroenterol Hepatol 2005;3:1043-1046.
21 Sayed-Tabatabaei FA, van Rijn MJ, Schut AF, Aulchenko YS, Croes EA, Zillikens MC, Pols HA, Witteman JC, Oostra BA, van Duijn CM: Heritability of the function and structure of the arterial wall: findings of the Erasmus Rucphen Family (ERF) study. Stroke 2005;36:2351-2356.

-22 Njajou OT, Houwing-Duistermaat JJ, Osborne RH, Vaessen N, Vergeer J, Heeringa J, Pols HA, Hofman A, van Duijn CM: A population-based study of the effect of the HFE C282Y and H63D mutations on iron metabolism. Eur J Hum Genet 2003;11:225-231.

23 Almasy L, Blangero J: Multipoint quantitative trait linkage analysis in general pedigrees. Am J Hum Genet 1998;62:1198-1211.

24 Boichard D: PEDIG, a FORTRAN package for pedigree analysis studied for large populations. Proceeding of the 7th World Congress, Montpellier, France. Genet Appl Livest Prod 2002;28-13.

25 Gambino R, Desvarieux E, Orth M, et al: The relation between chemically measured total iron-binding capacity concentrations and immunologically measured transferrin concentrations in human serum. Clin Chem 1997;43:2408-2412.

26 Tsung SH, et al: Immunological measurement of transferrin compared with chemical measurement of total iron binding capacity. Clin Chem 1975;21:1063-1068.

-27 Yamanishi H, et al: Total iron binding capacity calculated from serum transferrin concentration or serum iron concentration and unsaturated iron-binding capacity. Clin Chem 2003;49:175-178.
28 Aziz N, Munro HN: Iron regulates ferritin mRNA translation through a segment of its 5 ' untranslated region. Proc Natl Acad Sci USA 1987;84:8487-8492.

29 Breslow JL: Genetics of lipoprotein abnormalities associated with coronary artery disease susceptibility. Annu Rev Genet 2000; 34:233-254.

30 Swinkels DW, Janssen MC, Bergmans J, Marx JJ: Hereditary Hemochromatosis: Genetic Complexity and New Diagnostic Approaches. Clin Chem 2006 Apr 20; [Epub ahead of print] PMID: 16627556.

31 Hentze MW, Muckenthaler MU, Andrews NC: Balancing acts: molecular control of mammalian iron metabolism (review). Cell 2004;117:285-297.

32 Babitt JL, Huang FW, Wrighting DM, Xia Y, Sidis Y, Samad TA, Campagna JA, Chung RT, Schneyer AL, Woolf CJ, Andrews NC, Lin $\mathrm{HY}$ : Bone morphogenetic protein signaling by hemojuvelin regulates hepcidin expression. Nat Genet 2006;38:531-539.

33 Beutler E, Felitti VJ, Koziol JA, Ho NJ, Gelbart T: Penetrance of $845 \mathrm{G} \rightarrow>$ A (C282Y) HFE hereditary haemochromatosis mutation in the USA. Lancet 2002;359:211-218.

34 Frazer DM, Anderson GJ: Iron imports. I. Intestinal iron absorption and its regulation. Am J Physiol Gastrointest Liver Physiol 2005;289:G631-G635.

35 Makui H, Soares RJ, Jiang W, Constante M, Santos MM: Contribution of Hfe expression in macrophages to the regulation of hepatic hepcidin levels and iron loading. Blood 2005; 106:2189-2195. 